'THis level of chalcolithic occupation, however, lies at a depth of no more than $35 \mathrm{ft}$. from the summit of a mound which rises to a height of $80 \mathrm{ft}$. above water level; and it is known that there is a further ten feet of chalcolithic deposits below it before the neolithic strata are attained. In these, the accumulated relies of the original neolithic settlers extend downward for more than $30 \mathrm{ft}$. Here, Mr. Miles Burkitt, whose expert examination has been invoked, has found evidence, extending from below the painted pottery down to the $12 \mathrm{ft}$. level, of two main phases of neolithic culture, in which black or brown pottery is associated with tools of obsidian. To the beginning of the later of these two phases he assigns an antiquity which "can hardly be later than 5000 B.c., while the lowest level reached must date a thousand years earlier". As Prof. Garstang points out, the elaboration of the fortifications and dwelling site point to a well-advanced and highly organized existence at Mersin when Egypt, Babylonia, Crete and Europe were still in infancy. Impressive as the chronological range of this Cilician culture must appear to be, its significance for the archæologist is enhanced, when Prof. Garstang finds in certain details of his ceramic material evidence which appears to point not only to the East, but also to the West, forming a possible link with the Danubian area. Should further examination endorse this suggestion, Mersin will afford something approaching decisive evidence on a crucial problem of European prehistoric chronology of late much under discussion.

\section{Exhibition of Cypriote Antiquities}

AN exhibition of pottery of the Early Bronze Age at the Institute of Archæology of the University of London was opened by the Earl of Athlone, Chancellor of the University, on March 10. This pottery was excavated at Vounous in Cyprus by an expedition sponsored by the British School of Archæology at Athens and under the direction of Mr. James Stewart. The exhibition, as was pointed out by the Chancellor in declaring it open, is the first to be held in England of the results of an important excavation of purely British origin in Cyprus; and this fact is indeed of special significance in view of the attempts which have been, and are being, made to arouse interest in Great Britain in the early history and antiquities of Cyprus. The cost of the excavation was defrayed by subscription, among the principal subscribers being the University of Cambridge, Sir Charles Hyde, and Sir Charles Marston. The last-named has presented the main part of the finds allotted to him to the Institute of Archæology, and they form the nucleus of the present exhibition with supplementary loans from the Fitzwilliam Museum, Cambridge, and the Birmingham City Museum and Art Gallery. After the exhibition had been declared open Mr. Stewart gave an account of the site and its excavation. The Vounous site is a cemetery on the east and north sides of a low hill in the foothills of the Kyrenia Mountains. The north side had already been excavated by Dr. Dikaios, and the present work was confined to the east side. The tombs are open caves approached from a forecourt. Burial is in a contracted position, with burial gifts of pottery and food. 'The entrance was sealed with a single stone and covered in. Sometimes graves had been opened by an iron age grave-digger, who had again sealed the tomb after inserting a votive offering, with, as Mr. Stewart said, "confusing effect". The chronology of the site falls into three periods, dated tentatively from 2900-2500 B.C., 2500-2300 B.C. and 2300-2050 B.C.

\section{Approach to the Absolute Zero}

The second Poynting Memorial Lecture in the University of Birmingham was delivered by Dr. H. B. G. Casimir, of Leyden, on March 7, on "The approach to the absolute zero of temperature and some properties of matter at the lowest temperatures at present attainable". Dr. Casimir remarked that the subject, being one in which the combination of the theoretical and experimental had been so fruitful, was an appropriate one with which to commemorate a man who had in himself so remarkably embodied this combination. The definition of temperature in terms of an ideal gas enables us to say that the icepoint is $273.15^{\circ} \mathrm{K}$., but in practice the gas scale cannot be used directly below $1^{\circ} \mathrm{K}$., for at such temperatures gasos cease to exist. It is possible, however, by other methods, for example, the resistance of phosphor bronze, to extrapolate to $0 \cdot 2^{\circ} \mathrm{K}$., and very small temperature changes can be measured by using the magnetic properties of substances, so that measurements down to a few hundredths of a degree absolute or even less can be made with a good deal of confidence. Methods of experimenting were explained and the remarkable properties of helium II were described.

IT appears likely that it is impossible to solidify helium II, because the solid state requires stability of lattice, and if the helium atom cannot have less energy than $h_{v} / 2$, this may be sufficient to prevent the formation of a stable lattice no matter how low the temperature. Some special advantages of working at low temperatures were mentioned: Electric insulation is enormously improved; exceedingly high vacua can be attained--if care is taken to exclude helium, vacua down to $10^{-10}$ or perhaps $10^{-15} \mathrm{~mm}$. of mercury can be attained. Thermal insulation is greatly improved by the almost complete absence of radiation and of gas. Calorimetry is rendered relatively easy, for heat capacities are small, whereas by using the magnetic properties of a salt such as $\mathrm{KCr}\left(\mathrm{SO}_{4}\right)_{2} \cdot 12 \mathrm{H}_{2} \mathrm{O}$, temperature changes of the order of $0.001^{\circ}$ can be measured, so that the surprising conclusion emerges that the heat generated by allowing a mass of $1 \mathrm{gm}$. to fall through $0.01 \mathrm{~mm}$. would be capable of detection. The facts of superconductivity suggest the possibility of construction of galvanometers of prodigious sensitiveness and there would be no Brownian motion to cause trouble.

\section{Necker's Map of Scotland}

THE first geological map of Scotland, made by Louis Albert Necker in the year 1808, was exhibited by Mr. V. A. Eyles, of the Geological Survey, at a meeting 